\title{
A Study on the Development Process of New Standing Spray Designs based on the Service Design Approach
}

\author{
Naeri Kim ${ }^{1 *}$ and Hye Jin Kwon ${ }^{2}$ \\ ${ }^{1}$ Assistant Professor, Department of Interior Environmental Design, Dongyang Mirae University, Seoul 08221, Korea \\ ${ }^{2}$ Professor, Division of Smart Horticulture, Yonam College, Cheonan 31005, Korea
}

\section{ABSTRACT}

This study starts from the awareness of the problem that consumers are isolated from the standing spray product planning, and thus suggests effective designs and methods to the new standing spray design process. The ultimate purpose of this study is to suggest practicable new standing spray design outputs. Service design is based on customer experience, and thus it is intangible, process-centered and based on various relations.

Applying the service design to the development of new standing spray designs has the following significance. (1) Service design is an effective method for maximizing customer-centered experience. The customer-centered method of service design promotes practicability of new standing spray design. (2) Service design solves various problems by mediating opinions among various stakeholders. Effective and practicable solutions could not be found for new standing spray design despite various efforts that had been made for a long time. Since each step of the process is approached separately, it is necessary to take an overview of the whole process like service design. (3) Service design lays stress on process in which stakeholders participate. Participation and collaboration among stakeholders in the new standing spray design process will improve their satisfaction and enthusiasm to implement the new system.

Keywords: customer experience, flower, new wreath, participation, stakeholders

\section{Introduction}

Considering the characteristics of the Korean flower market in which consumption of cut flowers is concentrated on events, standing sprays have a significant meaning. standing sprays take up $85.2 \%$ of all consumption of cut flowers in Korea, and the standing spray market accounts for more than $30 \%$ of flower garden sales with 7 million standing sprays a year. Among them, reused standing sprays are estimated to take up approximately $20-30 \%$. Which disrupt the increase in consumption of real flowers, and this is found to cause the damage of approximately
KRW 55 billion a year to the farm sales (Lee and Lee, 2013). This distribution is mostly comprised of existing three-tiered standing sprays (existing standing sprays), which is based on the distinctive transport system of trucks due to their tall sizes, while also involving specialized disposal service companies and manufacturers. This specificity creates a closed market structure. As free market entry becomes more difficult, standing spray companies that lack design expertise begin to dominate the market, which causes general consumers to form a negative perception on standing sprays. Moreover, major issues are pointed out, such as reuse of flowers, standing sprays that are deterio-

\footnotetext{
This study is funded by the agricultural and bio-industry technology development project 'A study on the development of new wreath for expansion of flower consumption and strategies for promoting distribution system of wreath (Project No. 317069-2)'of the Korea Institute of Planning and Evaluation for Technology in Food, Agriculture, and Forestry (IPET).

Received: November 6, 2019, Revised: November 19, 2019, Accepted: January 15, 2020

First author: Naeri Kim, naeri79@naver.com, (i) https://orcid.org/0000-0003-4462-2875

*Corresponding author: Naeri Kim, naeri79@naver.com, (10) https://orcid.org/0000-0003-4462-2875
} 
rated and deformed, distribution methods, and gradual downscaling of flower farms. To resolve these issues, the government has led the diffusion of new standing sprays since 2011. However, despite the efforts from various related fields like the industry and academia to develop useful new standing spray stands, they are still not enough to expand the base.

Accordingly, this study begins from coming up with the issues of new standing sprays that fail to expand their base in the market. We focus on the fact that new standing spray designs thus far failed to be promoted as they are disregarded by the market and distribution conditions beyond the design issue. Moreover, we aim to propose useful designs that are actually used in the market by redesigning the overall process of new standing sprays, such as manufacturing $\rightarrow$ ordering $\rightarrow$ production $\rightarrow$ distribution $\rightarrow$ enjoyment $\rightarrow$ disuse.

To this end, we take an approach that is based on the concept and methodology of service design. Thus far, suggestions for new standing spray designs had limitations in that they were merely temporary expedients seeking alternatives in terms of formative and functional aspects like shapes and materials, approaching only within the existing boundaries of the standing spray industry. Thus, we intend to overturn the method of new standing spray designs. Since the goal of service design is not to design a material object but to design user experience, we think this study will help coordinate the requests of various stakeholders around standing sprays based on user-centered values, and ultimately suggest user-centered new standing spray designs.

\section{Research Methods}

The research flow is as follows. First, we come up with the progress, significance and problems of studies on new standing sprays conducted thus far, and determine the aim for new standing spray design development. Second, we examine the concept and aim of service design with focus on consumers, and conceptualized the methods and processes of service design. Third, we come up with outcomes by applying the service design methods and processes to the process of proposing new standing spray designs, and determine the significance and limitations.

The research methods are as follows. We analyze the significance and limitations of studies on new standing sprays based on previous studies, field research and survey, explain the concept of service design through literature review, and determine the design methods and processes, based on which we come up with new standing spray designs.

\section{Preceding research analysis}

Studies searched with related keywords on Korea Education \& Research Information Service (RISS) and NAVER Academic search were analyzed. There were two studies searched with 'new standing spray' on Korea Education \& Research Information Service (RISS), and the one other than our own research is a study that analyzed and proposed the general process from standing spray design to distribution and management, but is limited to the scope of standing sprays for congratulations and condolences (Table 1). There were 10 studies searched by expanding the scope of keywords to 'standing spray' + 'flower' on Korea Education \& Research Information Service (RISS), which can be categorized into (1) research on the overall process and suggestions of standing spray design, distribution and management (3 papers), (2) research on standing spray designs (5 papers), (3) research on processing standing spray materials (1 paper), and (4) research on the sociocultural factors that affect standing sprays (1 paper).

There were total 25 studies searched with 'standing spray'

Table 1. Preceding researches searched using a keyword 'new standing spray' on Korea Education \& Research Information Service

\begin{tabular}{ccc}
\hline Author & Subject & Publisher \\
\hline $\begin{array}{c}\text { Kwon, S., N.R. Kim, S.Y. Na, } \\
\text { and H.J. Kwon (2018) }\end{array}$ & $\begin{array}{c}\text { A study on the strategy for promoting distribution } \\
\text { system of new standing spray }\end{array}$ & Hortic. Sci. Technol. 31(Supple. II): 170. \\
Heo, B.G. and Y.J. Park (2014) & $\begin{array}{c}\text { Industry of cut-flower and cultural flower with a } \\
\text { happy or sorrow event in Korea }\end{array}$ & Seoul, Korea: Seo \& Ijae. \\
\hline
\end{tabular}


on Naver search engine, which can be categorized into (1) research on overall satisfaction and suggestions of standing spray design, distribution and management (3 papers), (2) research on standing spray designs (8 papers), (3) research on processing standing spray materials (5 papers), and (4) research on the sociocultural factors that affect standing sprays (9 papers). They were focused on designs related to standing spray materials or on the local areas of design on standing spray material processing methods, but recently there are more studies that analyze and suggest the overall process of standing sprays such as design, distribution, management and publicity, considering the effects of standing sprays on the flower culture in Korea.

Lee and Lee (2013) and Kim et al. (2016), who discuss the overall process of standing spray design, distribution and management and make structural suggestions for the system, are analyzing more subdivided demands from the users' perspective. Moreover, they have significance in that they take a multilateral and holistic approach in which policies, distribution and publicity operate in a single product process. Lee and Lee (2013) are making attempts for their research to be used more effectively by suggesting an overall process of new standing spray distribution and management and proposing new standing spray stand designs. As such, we conducted a market research on designs suggested by different studies or designs proposed in terms of policy, as well as various new standing spray stand designs that have been distributed in the market, analyzed their strengths and weaknesses, and set the direction for new standing spray stand design.

\section{Field research}

Field research in Korea was conducted from December 2017 to February 2019. Various forms of new standing spray stands have been developed and distributed, such as the form that changed the previous three-tiered standing spray structure to metal, A-frame new standing spray stand, $\mathrm{X}$-shaped folding new standing spray stand, aluminum new standing spray stand, plastic piece built-up new standing spray stand, wood fixed new standing spray stand, etc. However, they failed to be distributed continuously in the market, causing issues such as instability (light material), lack of design (dull, inappropriate proportion), low usability (built-up type separated into many pieces), high unit cost (aluminum), low load efficiency (fixed type), etc. Fig. 1 shows the analysis of new standing spray stand designs in the market based on stability, aesthetics, usability, and economic feasibility.

In 2011, the Ministry of Agriculture, Food and Rural Affairs attempted to improve the form to A-frame standing spray stands, but they failed to settle in the market due to inadequacy in the distribution system that had been formed by the previous three-tiered standing sprays (existing standing sprays) for a long time, reduced size, weakness in price competitiveness and stability, and complicated operation method.

The X-shaped folding new standing spray stands that have been used with good response in the market until recently have the benefit of being easy to carry and load with the two boards connecting their poles crossed in an $\mathrm{X}$-shaped form and the center fixed with pieces as shown

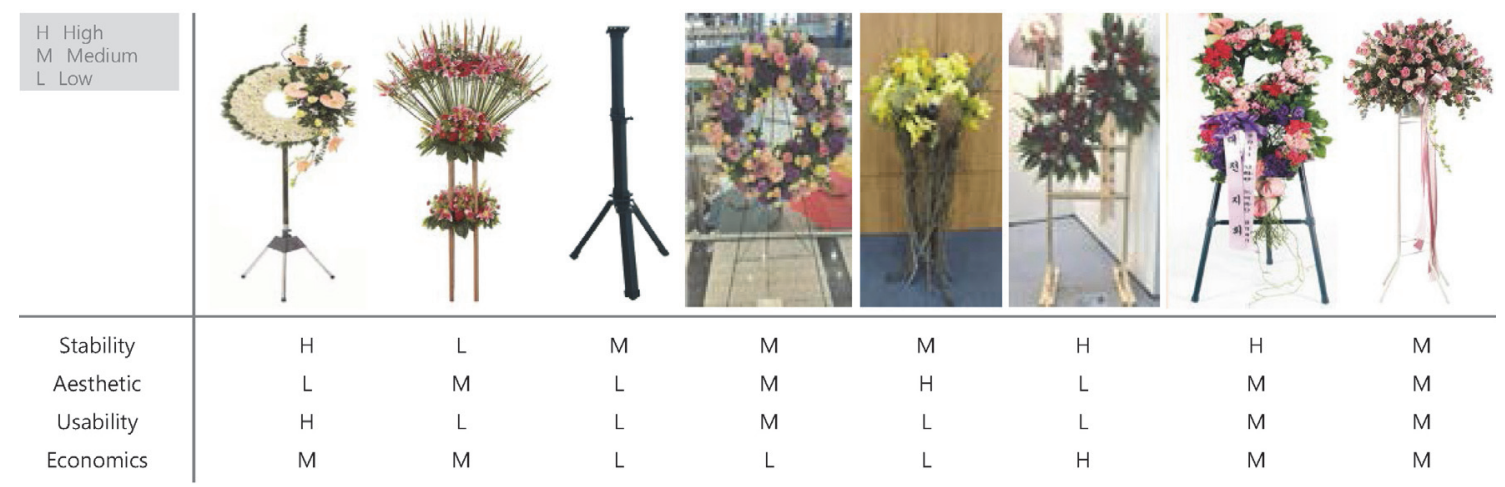

Fig. 1. Images and characteristics of new standing spray stands of all types currently available at the market. 


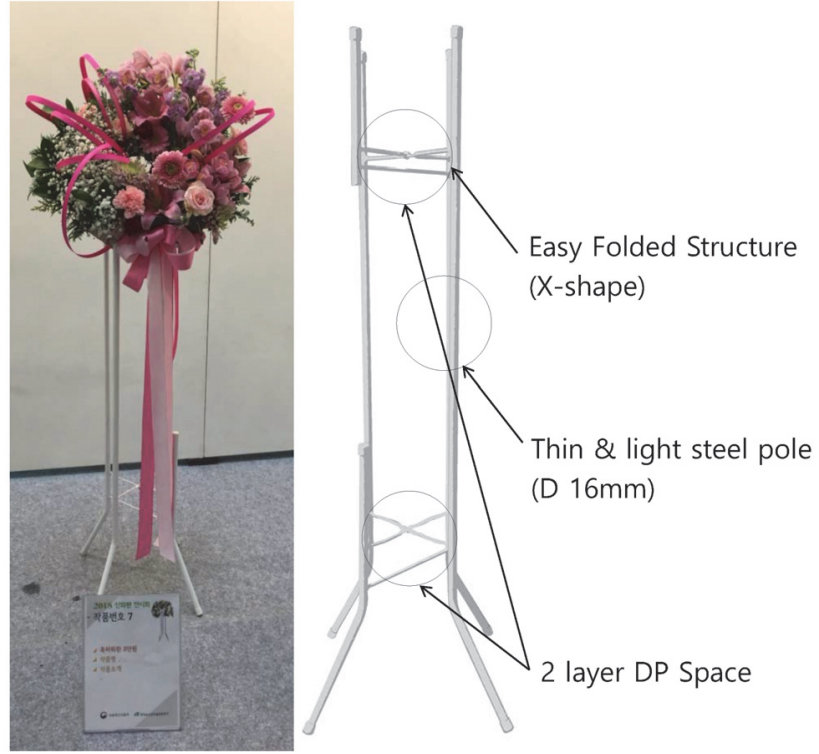

Fig. 2. X-shaped folding new standing spray stand and its frame structure.

in Fig. 2, thereby reducing volume by easily folding them. The standing spray can be arranged in two tiers if necessary, thereby enabling product compositions in various price ranges. As such, they have strengths in terms of economic feasibility and functionality, but the light and thin $16 \mathrm{~mm}$ steel framework member has a weakness in stability, the load and damage on the X-shaped piece fixture that is the key driving part has a weakness in functionality, the lower part with a poor proportion compared to the flowers has a weakness in aesthetics, and the annular form has a weakness in design efficiency in a standing spray installing environment where the focus is to look in front. The factor that keeps this new form from being actively used in the market despite no fatal functional and aesthetic flaws is price competitiveness compared to exisiting standing sprays. The distribution process of existing standing sprays - ordering, production, transport and installation, disuse shows an organic connection of stakeholders that have been differentiated, specialized and professionalized in each step for a long time in the market. The new standing spray form fails to be applied to this distribution structure and thus requires separate workforce and distribution system. As a result, the standing spray market that is attractive but has a high entry barrier keeps the new form from being widespread. In the end, it is necessary to expand the scope to the labor costs and distribution costs required in the entire process of use, rather than viewing price competitiveness in terms of merely reducing direct unit costs of standing sprays such as the wages for making standing spray stands and the amount of flower materials.

\section{Implications}

According to previous research, the aim of new standing sprays that have been released and distributed in the market can be classified into (1) reducing conspicuous size, (2) promoting use of real flowers, (3) preventing reuse of flowers, and (4) developing standing sprays and standing spray stands at lower costs than old standing sprays. In other words, the goal of developing a new standing spray stand is based on the ethical consciousness of a 'must' to promote the flower culture, and it is aimed at 'finding an alternative focused on costs' in terms of method to dominate the competitive advantage in the market in advance. The alternative thinking of cost reduction in the old framework is a supplier-centered approach that excludes consumers. Like a general product development process, 'standing sprays' must also be regarded merely a product, and thus it is necessary to start product planning with the fact that there is a lack of consumer-oriented thinking that is the most fundamental start: "Why is the user not at the center of the new standing spray design?" In other words, this indicates the shift in the way of thinking that 'responds to consumer needs' instead of 'doing something that must be done'. The key issues are the fact that the consumer (person who pays) is differ from the use (person who enjoys the product) and thus the consumer (person who pays) does not directly experience the product quality, and thus this fails to form a virtuous cycle of product purchase and enjoyment. The fact that consumers are isolated by the product result in the product development to be focused on manufacturers and managers. As a result, the industry is developed in an abnormal way, considering only economic feasibility and operational efficiency unlike the consumer needs for the product, such as the changing pattern of standing spray designs according to the distribution method instead of by the request of consumers.

Another problem is the burden of handling flower wastes 


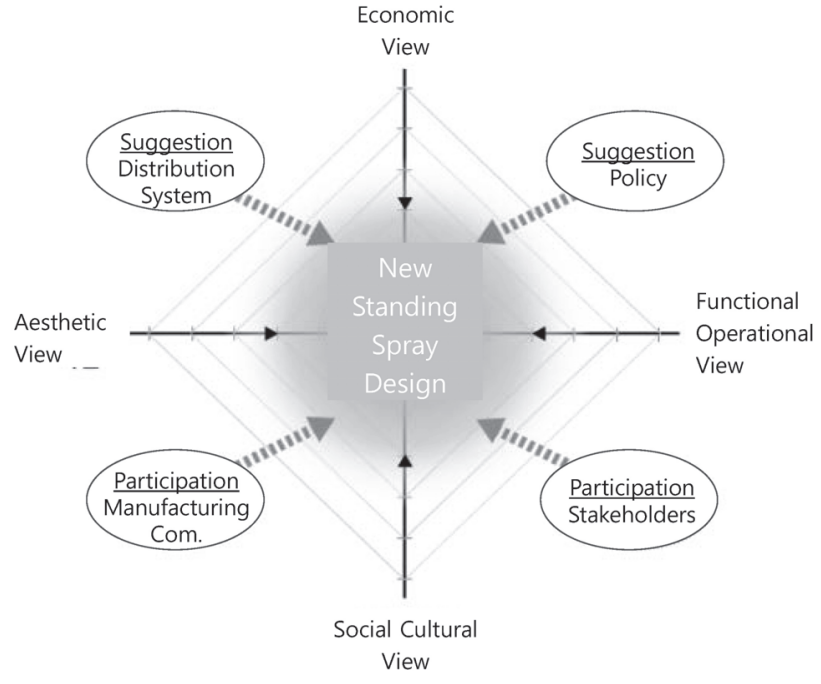

Fig. 3. Concept diagram of design approach to new standing spray.

after use, which originates from the nature of the material. This forms a deformed industrial structure in which separate flower disuse companies are involved, and they gain profits by reusing flowers in the process.

Accordingly, this study took a consumer-oriented approach and set the aim to suggest a new standing spray system and design that 'consumers enjoy' and that 'reflects the characteristics of flowers and the Korean standing spray culture that has been growing naturally'. As shown in Fig. 3 , new standing spray designs must be approached within the cooperative relations among various related fields. Thus, in terms of method, we aim to set and coordinate relationships among various stakeholders and approach it based on the concept and methodology of service design that ultimately designs consumer experience beyond physical design.

\section{Design application methods}

Since the Industrial Revolution where the focus was on efficiency in mass production, the key issue of good design was the one with high functionality and economic feasibility. As a result, design was all about how the 'shape of the object' will be made, that is, the physical form of making. However, with the recent changes in the concept of perception and social values, design encompasses all actions and matters that occur based on creative mind, beyond the in- visible concept (Lee and Pyo, 2012). In other words, there is more stress on usability that had been neglected, and on behavior and experience. Now the key is 'how to make consumers feel' instead of 'what to make', with the design focus shifting from product to user, naturally heading toward the direction in which there is convergence with other fields such as science and humanities as well as participation of various stakeholders beyond the formative concept of shape and material.

Service design is a concept and methodology defined within these changes, and it analyzes and resolves the complicated issues with focus on the user. Service design values the process of repeated feedback through action, since user experience is the object of design. Started out as a differentiation strategy in public service and IT industry, service design (Han, 2009) is recently expanded and used as a concept that embraces all kinds of design required in all service areas. Table 2 summarizes the concept of service design defined in various fields and institutions.

Service design is a compound of 'service' and 'design'. By dictionary definition, service is a concept that extensively encompasses labor that functions outside the labor process of producing material goods (Park, 2011). Service is invisible and intangible; it is an experience good that keeps its content and value unknown unless experienced. Thus, service is characterized by intangibility, heterogeneity, non-separability, and volatility. Service design is a methodology to more elaborately and specifically reveal service attributes combined with the universal features of design understood as physical, tangible, semantic and symbolic characteristics (Park, 2011). In sum, the concept of service design is defined as the overall problem-solving process that handles the direct requests and needs of users in terms of design, based on the user sentiment and experience (Lee and Nah, 2013). This process brings change to the thoughts and behaviors of users, thereby creating experience.

The key significance of implementing the service design perspective in new standing spray design is as follows. (1) Service design is an effective method to bring innovation to customer-centered experience value and thus can be used suitably in developing consumer-oriented product policies as well. (2) Service design is based on creation by collaboration among different fields as it views not the product 
Table 2. Definition of service design

\begin{tabular}{|c|c|c|}
\hline Field & & Definition \\
\hline \multirow{4}{*}{$\begin{array}{l}\text { Academic } \\
\text { field }\end{array}$} & $\begin{array}{l}\text { Copenhagen Interaction Design } \\
\text { School (CIID, 2008) }\end{array}$ & $\begin{array}{l}\text {-Focused on the experiment for drawing 'good idea' with tangible and untangible things } \\
\text {-Multi-disciplinary field with design, management, process engineering and etc. } \\
\text {-Whole process design and for human }\end{array}$ \\
\hline & Stefan Moritz (2005) & $\begin{array}{l}\text {-To provide attractive service to customer } \\
\text {-To improve and innovate existing service for effectiveness }\end{array}$ \\
\hline & UK Design Council (2010) & -To make service which is effective, attractive and useful \\
\hline & $\begin{array}{l}\text { Koln International School of Design } \\
\text { (KISD) (Birgit Mager, 2009) }\end{array}$ & $\begin{array}{l}\text {-To make service which is convenient and attractive in aspect of customer } \\
\text {-To make service which is effective and different in aspect of customer }\end{array}$ \\
\hline \multirow{4}{*}{$\begin{array}{l}\text { Business } \\
\text { field }\end{array}$} & Engine Service Design (2010) & -To improve communication, product function, satisfaction and efficiency based on human \\
\hline & Frontier Service Design (2010) & -The method which is for understanding customer's needs totally and deeply \\
\hline & Continuum (2010) & -To develop the work environment, tools and process which afford brand concept \\
\hline & Livework (2010) & $\begin{array}{l}\text {-Design process and ability for developing service } \\
\text {-To design some touchpoint following timeflow for customer's various experiment }\end{array}$ \\
\hline
\end{tabular}

Note. Reprinted from “A study on the service design process based on emotion-experience”, by K.A. Lee and K. Nah, 2013, Journal of Digital Design, 13(1), pp. 415-426.

but the human experience as an object of design, through which it solves complicated and entangled problems. The new standing spray policy that fails to come up with a remedy due to the conflict of interests requires collaborative and holistic approach in terms of service design. (3) Service design lays stress on the process in terms of method. Various stakeholders in the standing spray industry including manufacturers and consumers participate in the process of service design development together and thus are bound to form a consensus, which contributes greatly to the executive ability for the developed design and improves satisfaction of various stakeholders that participated, thereby forming a virtuous cycle.

Since the object of design is intangible and situational, service design has complex and mutual processes in correlation with various factors of problems, as well as the following characteristics. Design is developed based on collaboration among various fields based on observation of user demands, and since it is intangible and experiential, it is evaluated after implantation, and then back to definition and analysis of the results. The service design process can be summarized as 'understanding $\rightarrow$ defining $\rightarrow$ ideation $\rightarrow$ prototyping and testing $\rightarrow$ implementing, and the process and key methods of each step of service design reconstructed with focus on the designer's role are as shown in Table 3.
The feasibility of new standing spray designs can be increased by applying the characteristics of service design considering the user's experience and carried out in a participatory process to the proposal of new standing spray designs that fail to find a remedy in all the complicated situations. We applied the service design process and methods to the process of coming up with new standing spray designs, and determined the significance and limitations.

\section{Results and Discussion}

We approached with field research and observation, one of the key methods of service design, for fundamental understanding of the problems in the understanding step. Stakeholders in the standing spray market can be classified into users, producers, distributors and providers, and we conducted in-depth field interviews and a survey on the stakeholders of these four groups.

The survey was conducted from December 2017 to April 2018 on total 148 participants including workers in the standing spray industry, workers in other flower-related industries, and consumers in Korea. The structure of the survey is as shown in Fig. 4. The participants were asked questions about the problems of old and new standing sprays in terms of design, distribution and publicity. Users 
Table 3. Process and tools of service design at each step

\begin{tabular}{|c|c|c|c|}
\hline Step & Method \& tool & & Contents \\
\hline \multirow{3}{*}{ Understanding } & \multirow{3}{*}{$\begin{array}{l}\text {-Preliminary research (market } \\
\text { analysis, preliminary research } \\
\text { analysis, etc.) } \\
\text {-Field research (expert advice, } \\
\text { deep interview, focus group } \\
\text { investigation, observation, } \\
\text { shadowing, etc.) }\end{array}$} & 1) Understanding & $\begin{array}{l}\text {-Understanding project goal } \\
\text {-Collecting whole information } \\
\text {-Setting the guideline for customer researching }\end{array}$ \\
\hline & & 2) Observe & $\begin{array}{l}\text {-Selecting and developing suitable method through } \\
\text { research framework } \\
\text {-Detail plan for researching } \\
\text {-Field research }\end{array}$ \\
\hline & & 3) Analyze & $\begin{array}{l}\text {-Analyzing data } \\
\text {-Discovering insight through relation with data }\end{array}$ \\
\hline Defining & $\begin{array}{l}\text {-Personas } \\
\text {-Location plan } \\
\text {-Journey map }\end{array}$ & 4) Define & $\begin{array}{l}\text {-Substitute personas } \\
\text {-Substitute customer journey map }\end{array}$ \\
\hline \multirow[b]{2}{*}{ Ideation } & \multirow{2}{*}{$\begin{array}{l}\text {-Brainstorming } \\
\text {-Affinity diagram }\end{array}$} & 5) Ideation & -Ideation to solution freely \\
\hline & & 6) Selecting & $\begin{array}{l}\text {-Setting design development direction } \\
\text {-Suggesting concept }\end{array}$ \\
\hline Prototyping test & $\begin{array}{l}\text {-Drawings } \\
\text {-Scenarios }\end{array}$ & 7) Prototyping $\&$ test & $\begin{array}{l}\text {-Suggesting detail solution } \\
\text {-Prototyping and testing repeatedly }\end{array}$ \\
\hline Implement & $\begin{array}{l}\text {-Service guides } \\
\text {-Blue print }\end{array}$ & 8) Implement & $\begin{array}{l}\text {-Delivering output to customer } \\
\text {-Detail plan for implement service } \\
\text {-Getting feedback and reflecting opinions }\end{array}$ \\
\hline
\end{tabular}

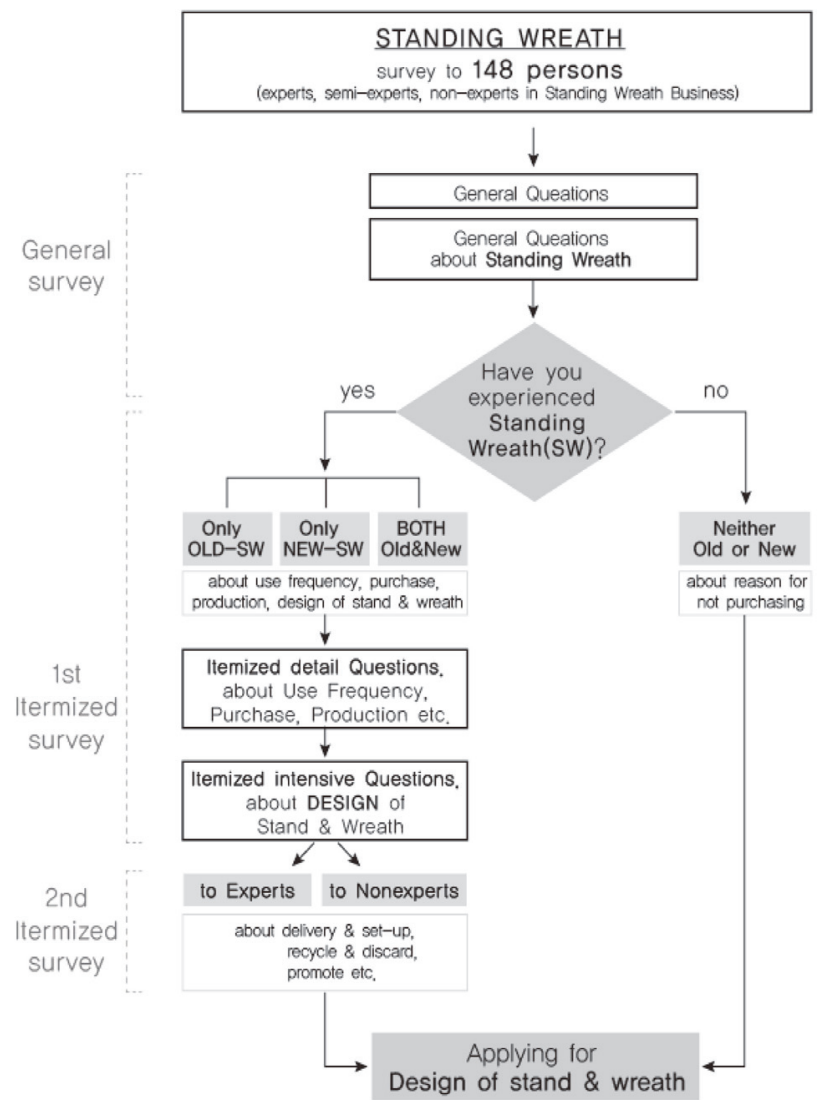

Fig. 4. Structure of survey. who used neither of the two types were asked why they did not use standing sprays, thereby coming up with implications for new standing spray design. In terms of design, it seemed necessary to secure freshness and recyclability of flowers in designing new standing sprays, as well as to improve flower design and obtain differentiation. For new standing spray stands, it was necessary to improve the functional aspects such as stability, durability and ease of use, obtain differentiation in designs, and resolve the issue of disposability of materials. For the overall product system such as distribution and publicity, it was necessary to save costs by building a stable delivery and installation system to deliver standing sprays to all areas of the country at the exact time, as well as to use a stable system for disuse as well. Consumers claimed they need a service to check the status of delivery and recycle the flowers. IT was also necessary to diversity publicity for new standing sprays to be established in the market and improve quality.

Consumers who have experience using standing sprays pointed out that it is necessary to more improve the aspects of collection, disuse and enjoyment than design in order to improve the standing spray culture and secure market 
settlement. Those not interested in standing sprays claimed it is necessary to develop various products for subdivided targets so that there is a competitive advantage over competitors by improving design and securing freshness.

The results of the survey can be analyzed as follows. standing spray suppliers lay stress on building a distribution system similar to that of the existing three-tiered standing spray and approach the direction of improvement within the existing production and distribution system of standing sprays, whereas consumers emphasize the aspects in which they can purchase and enjoy standing sprays from their perspective, such as checking the status of delivery, recycling and enjoying the flowers, and improving the design quality. This indicates that suppliers and consumers have different perspectives in approach. It is necessary to approach the development of new standing spray stands from the consumer-oriented view instead of supplementing and replacing the existing method that approaches it from the supplier-oriented view, and consumers are demanding a more holistic process and customer-centered change.

We conducted in-depth interviews and field observation and research on stakeholders in Korea and overseas from 2017 to 2019. Table 4 shows the needs of these stakeholders. Users claimed it is necessary to (1) improve the negative perception by improving the quality of standing spray design, and (2) share the perception and form consciousness about the unethical issues of the current standing spray distribution (not perceiving the issue of reusing flowers). This is the fundamental rights of consumers to know and thus is essential for building a virtuous cycle by mutual feedback of consumers and producers. Producers pointed out the importance of (1) maintaining low costs of standing spray stands, (2) using the established ordering, delivering and removing system in the existing standing spray market, and (3) promoting new standing sprays. This showed the perspective of producers who want to take an alternative approach within the frame of the existing standing spray market. For suggestions that break away from the existing market, they pointed out that there must be a system that involves all of consumers, producers, distributors and providers by building and promoting a suitable system. In other words, effective improvement can be made possible only by proposing a general system related to profits in addition to forming a conscious consensus. Distributors also (1) emphasized the use of the existing system. Providers had thoughts in multiple angles about the actual problems as the place where the end products are gathered. They made suggestions in terms of environmental friendliness and ethics such as (1) solution to the burden of flower wastes (supply of crushers/disintegrators) and (2) reducing the size of new standing sprays. They also pointed out the need for a certain amount of forcibleness, and suggested that there must be policy support and publicity such as (3) legalization of the new standing spray policy and issuance of official documents. They also requested (4) minimized space necessary for storage and shape that is easy to load

Table 4. Needs of each stakeholder for new standing spray design

\begin{tabular}{|c|c|}
\hline & Needs of each stakeholder for new standing spray design \\
\hline User & $\begin{array}{l}\text {-Qualitative improvement of standing spray } \\
\text {-Improve awareness of standing spray product } \\
\text {-Share problems and formation of consciousness 'the problem of standing spray', }\end{array}$ \\
\hline Producer & $\begin{array}{l}\text {-Low-priced new standing spray stand } \\
\text {-If new standing spray stand price is up, we have to suggest the system of product recovery } \\
\text {-Promotion is important } \\
\text {-Using existing standing spay system } \\
\text {-If existing standing spay system isn't used, we have to suggest the whole system of ordering, producing, and distributing, etc. }\end{array}$ \\
\hline Distributor & $\begin{array}{l}\text {-Using existing standing spay system } \\
\text {-If existing standing spay system isn't used, we have to suggest the new distribution system. }\end{array}$ \\
\hline Provider & $\begin{array}{l}\text {-Minimizing new standing spray stand volume in case of stacking } \\
\text {-Minimizing facility damage in case of fixing to space } \\
\text {-Setting system of flower waste disposal } \\
\text {-New standing spray policy have to be done by top-down system }\end{array}$ \\
\hline
\end{tabular}


in terms of standing spray stand design, and (5) minimization of damage to facilities for smooth cooperation among internal departments when fixing and installing the standing spray.

Defining begins by being aware of the problems derived in the understanding step. Nothing can be new if we consider improving only the design of the new standing spray stand with many attempts made thus far, and approach within the existing frame of standing spray distribution. Rather, we need an omnidirectional approach in which various fields related to the standing spray industry can perform their roles in their places, with consumers at the center. Moreover, there is a need for a gradual yet fundamental approach since there is fatigue and distrust prevailing due to failure after countless new attempts. Therefore, (1) policy approach to change the standing spray culture and distribution structure as well as (2) process to improve consumer awareness are needed. While the former is an obligatory act based on forcibleness in certain part, the latter can be a movement based on proactiveness of the consumers, which can be a driving force of sustainable improvement with a great ripple effect. (3) standing spray stand design development is based on the diversification strategy. It is carried out in long-term and short-term strategies as a diversified solution to promote gradual improvement of awareness by approaching the market in a friendly way. We aim to pursue designs based on the needs of each stakeholder that are friendly to the existing standing spray system that is well established in the short run, and propose designs that support gradual improvement (standing spray culture enjoyed by consumers, standing spray culture considering environmental friendliness, restoration of an ethical consumption structure, revitalization of flower farms, etc.) for continuous standing spray culture development in the long run.

The main direction of ideation can be summarized as shown in Fig. 5 based on the diversification strategy. We suggested three types of new standing spray stand designs supporting diversification: entry-friendly type, advanced type, and value-creative type. (1) The entry-friendly new standing spray stand suggested as a market-friendly design aims for improved usability, stability and durability as well as low costs, and is suggested in two forms: objet shape and faced shape. (2) The advanced new standing spray stand aims for advancement and premium value by apply- ing two-tone shades and molding while maintaining the existing X-shaped structure of the new standing spray stand currently well received in the market, and it is designed to blend well with various colors of the flowers. The clamp-type holder system was supplemented by improving the previous structure in frontal arrangement. The advanced type has significance in that it offers various design options while supplementing aesthetics. (3) The value-creative new standing spray stand was suggested as a space installation type instead of objet, aiming for sustainability, environmental friendliness and new standing spray culture. It has a self-supporting form to minimize spatial damage when installing, and it can be installed according to each spatial condition as it is in built-up-type pieces. It was suggested as a concept to use for graphics and benches when not used for standing sprays. It provides 'sustainability' by reducing use of disposable materials by fixing and installing the standing spray stand, and aims to induce structural change so that consumers can 'consume values' by reducing the wasteful behavior in the entire process of transport, installation and disuse by reducing the size of standing sprays.

All design suggestions are made to reduce the size from the existing three-tiered standing sprays and secure volume with inexpensive and coarse or reused materials, while improving harmony and aesthetic completeness so that the standing spray stand can be viewed as an objet along with flowers. In addition, we also suggested (4) subsidiary materials such as banners for area composition. Furthermore, we (5) developed a round standing spray tray for consumers to enjoy the flowers as potted flowers or hand-tied cut flowers put into the tray. The flowers can be taken home by consumers after the event so that the standing sprays can be 'enjoyed' rather than 'seen', putting consumers back to the center of the standing sprays. Moreover, the easy arrangements also help facilitate standing spray market entry of general flower shops.

In the prototyping and test step, we produced prototypes of designs proposed from 2017 to 2019, and then simulated the service journey in the process from production to delivery by meeting with stakeholders. We held a second meeting after revision and improvement in light of the opinions, thereby holding total two meetings (one each in 2018 and 2019) with workers in the flower industry throughout vari- 


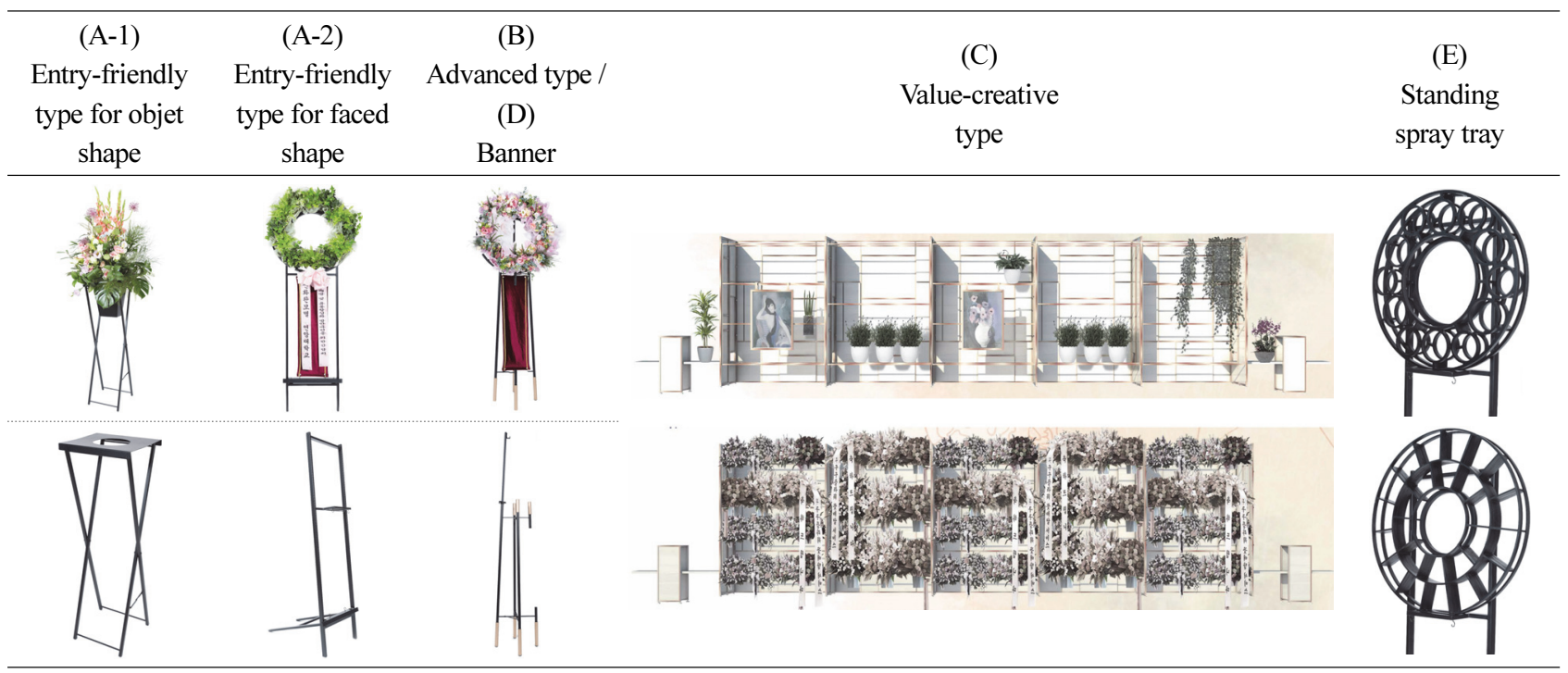

Fig. 5. New standing spray design proposals: (A) entry-friendly type, (B) advanced type, (C) value-creative type, (D) subsidiary materials_banners, (E) subsidiary materials_standing spray tray.

ous fields to collect opinions in terms of usability of the prototypes, experiential view, as well as policy and administrative aspects. Some of the significant views from the first meeting in 2018 included the need to develop standing spray stands with inexpensive materials to save costs, suggest standing spray arrangement methods to recycle flowers, and develop hardware to support distribution so that the existing transport system can be used. The meeting in 2019 was held after reflecting these needs. The key opinions of the second meeting included the need to build a system for continuous activation in terms of policy, since the plans for design, distribution and publicity are favorable. They also laid stress on the need to provide policy support in the industrial settings, since this system requires initial investment and publicity.

In the implementing step, we prepared for implementation by first creating a data package that mapped out the proposed designs for mass production. We suggested a service journey map for customers in each design to give the perception that consumers perform the central role in service and can enjoy the products. The design is changed from a straight, one-way form to loop type, with consumers at the center. It can be seen that consumer, supplier, distributor and provider mutually affect one another in a cycle and perform participatory roles. This is schematized and clearly shown in Figs. 6 and 7. The value-creative type

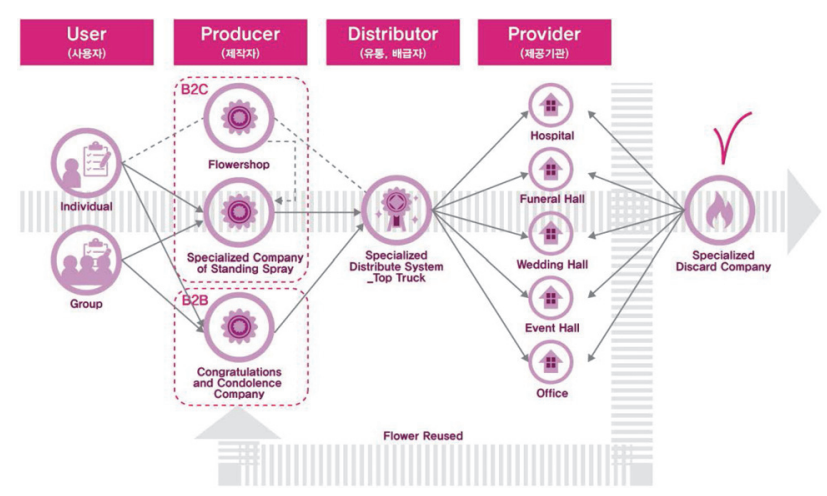

Fig. 6. User journey map of existing standing spray stand.

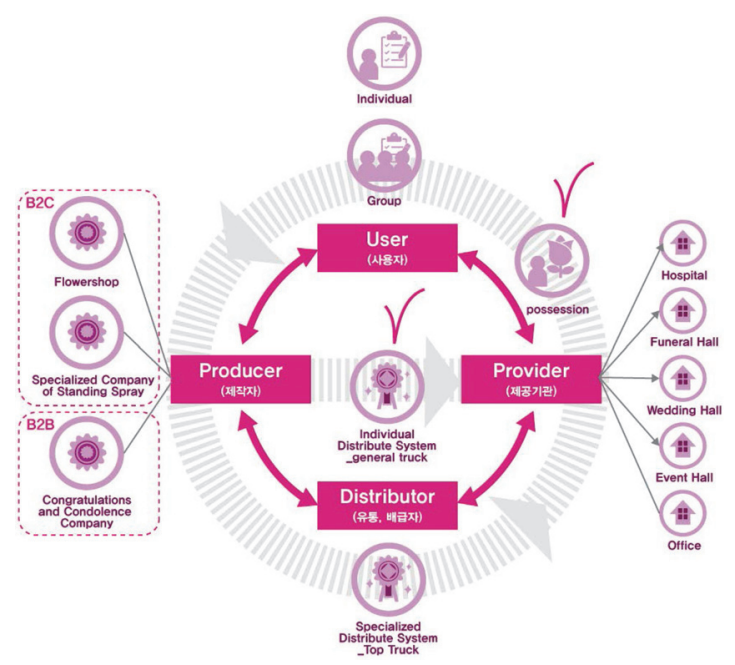

Fig. 7. User journey map of new standing spray stand through entry-friendly type \& advanced type. 
is based on the circular type but is intuitive due to the more simplified service steps, and has a direct service flow.

In addition, it is necessary to produce campaign leaflets for conscious consumption to improve the awareness on new standing sprays and distribute them to consumers, and also distribute new standing spray design manuals to small flower shops for free to facilitate their market entry, thereby contributing to overcoming the weaknesses of the new standing spray market and expanding the base. This can also serve as the guidelines to maintain the qualitative level when implementing the new standing spray design.

\section{Conclusion}

This study has significance in that it proposes new standing spray designs from the perspective of service design starting from the awareness of the problem that consumers are isolated from the standing spray product planning, and suggests effective designs through the process. Service design is approached in a user-centered view away from the efficiency-oriented design concept with focus on functionality and economic feasibility, and its object is the holistic suggestion for intangible situations such as human sentiments and experiences.

Adopting service design in new standing spray design has significance as it puts users right back to the center that actually enjoys the standing spray service. This is because service design is a useful method and tool for customer-centered product strategies. Moreover, since the purpose of service design is to create human experience, it is based on participation, collaboration and coordination of various fields and stakeholders. Accordingly, a multilateral and holistic approach can have significance in new standing spray design, which had failed to easily find a remedy due to the conflict of various interests that set in for a long time. Based on participation and collaboration, stakeholders can form sufficient understanding and con- sensus about the problems, which may lead to actual implementation and improve satisfaction in the process.

In service design, not only the output but also the dynamics of the process is very important, in which stakeholders in various fields voluntarily participate and reflect and make decisions. Since this study is a general outline and analysis of the process and outcome of approaching the new standing spray design process in the perspective of service design, further research shall discuss the effect of the participatory decision-making process on design outcomes.

\section{References}

Han, S.R. 2009. A study direction for evaluation of public service based on service design. Master's Thesis, Ewha Womans University, Seoul, Korea.

Heo, B.G. and Y.J. Park. 2014. Industry of cut-flower and cultural flower with a happy or sorrow event in Korea. Seoul, Korea: Seo \& Ijae Publishing.

Kim, E.J., K.W. Han, and C.H. Pak. 2016. Current status of use artificial flower and analysis of polluting substance. Hortic. Sci. Technol. 34(Suppl. I):213-214.

Kwon, S., N.R. Kim, S.Y. Na, and H.J. Kwon. 2018. A study on the strategy for promoting distribution system of new standing spray. Hortic. Sci. Technol. 36(Suppl. II): 170 .

Lee, A.K. and J.H. Lee. 2013. Improvements of custom and distribution system of standing sprays. Hortic. Sci. Technol. 31 (Suppl. I):185-186.

Lee, K.A. and K. Nah. 2013. A study on the service design process based on emotion-experience. J. Digit. Des. 13(1):415-426.

Lee, W.S. and H.M. Pyo. 2012. Service design innovation. Seoul, Korea: Ahngraphics publishers.

Park, E.T. 2011. Economic dictionary. Seoul, Korea: Kyungyoun publishing. 